\title{
А.М. Либман
}

Мюнхенский университет, Германия

\section{Децентрализация кризиса, слабости и ответственности ${ }^{1}$}

Аннотация. Кризисы нередко ведут к ослаблению субнациональных органов власти, но в некоторых случаях способствуют децентрализации. Однако содействует ли децентрализация поиску оптимальных антикризисных стратегий? Существует ряд аргументов, позволяющих предположить, что децентрализованные системы будут лучше справляться с кризисами, чем централизованные. В настоящей статье, однако, рассматриваются два сценария («децентрализация слабости» и «децентрализация ответственности»), в которых кажущийся рост автономии субнациональных органов власти связан с существенными проблемами. Децентрализация слабости возникает, когда центральные органы власти - в силу тех или иных причин - отказываются от проведения активной антикризисной политики. В этой ситуации меры, предпринятые регионами, хотя и являются определенной компенсацией бездействия центра, порождают ряд других проблем - невозможность учета экстерналий, риски идеологизации политики и недостаточного учета экспертного знания. Децентрализация ответственности возникает, когда регионы принимают на себя полномочия по принятию антикризисных решений, но центр сохраняет контроль за ресурсами - регионы вынуждены основное внимание уделить конкуренции за доступ к центральному финансированию. Для современной России риски реализации этих сценариев являются существенными.

Ключевые слова: деиентрализачия, знание о спещифической ситуачии в регионе, кризис.

Классификация JEL: H12, H77.

DOI:10.31737/2221-2264-2020-46-2-10

Внешние шоки (например, экономические кризисы или войны) влияют на взаимодействие между регионами и центральной властью, на степень политической и административной децентрализации. Во многих случаях кризисы ведут к ослаблению автономии субнациональных органов власти - необходимость консолидации ресурсов и их целенаправленного использования с целью преодоления кризиса способствуют росту значимости центрального бюджета и большей координации действий регионов (Wallis, 1984; Flanagan, 1999; Arias, 2013; Bolgherini, 2016). Однако не все кризисы сопровождаются ростом влияния центра: в некоторых случаях, наоборот, именно субнациональные органы власти усиливают свою автономию (t'Hart et al., 1993). Разворачивающаяся на наших глазах пандемия коронавируса является ярким примером такой динамики - в США, Бразилии и России штаты и регионы играют ключевую роль в определении характера и типа ограничений.
В Германии земли, обладающие конституционной полнотой власти в вопросах здравоохранения, в марте начали самостоятельно вводить карантинные меры, а в начале мая - снимать и модифицировать установленные ограничения с учетом местных особенностей.

$$
\text { Субнациональные органы власти }
$$
обладают в условиях кризиса важным преимуществом: знанием текущей ситуации и особенностей развития кризиса в регионе (local knowledge). Необходимость использовать это специфическое знание о текущей ситуации в регионе является важным аргументом в пользу децентрализации государственного управления в целом (Hayek, 1945). Разворачивающийся кризис делает фактор знания о специфической ситуации в регионе еще более важным, поскольку ситуация развивается быстро и непредсказуемым образом (Sobel, Leeson, 2007). Эффективность принимаемых мер зависит от точности и скорости реакции органов власти и адаптации к кон-

\footnotetext{
${ }^{1}$ Исследование выполнено при поддержке Министерства образования КНР (МОE Project of Key Research Institute of Humanities and Social Sciences in Universities of China (Center for Russian Studies of East China Normal University), Project Number: 16JJDGJW004).
} 
кретным вызовам, которые гораздо быстрее и проще обеспечить на месте, чем в центре. Столкновение различных групп интересов в центре может еще больше замедлить реакцию на кризис. Во многих случаях знание о специфической ситуации в регионе сложно формализовать и систематизировать, что затрудняет передачу информации на более высокие уровни административной и политической иерархии. Таким образом, децентрализация может оказаться әффективной стратегией антикризисных мер (Tofall, 2020), во всяком случае для кризисов, течение которых обладает ярко выраженными местными особенностями, - кризисы, для которых местная специфика не столь важна (например, войны), преодолеть с помощью децентрализации едва ли возможно. При этом децентрализованные решения должны сопровождаться постоянной координацией действий субнациональных правительств и обменом информацией между ними. Наладить эту координацию непросто; судя по всему, именно на эту стратегию в условиях пандемии ориентируется Германия ${ }^{2}$.

Проблема состоит, однако же, в том, в каких условиях происходит децентрализация и какими стимулами она вызывается. В этой статье мы обсудим два примера дисфункциональной децентрализации в условиях кризиса, когда реакция субнациональных органов власти на кризис или в принципе не позволяет использовать ресурс знания о специфической ситуации в регионе, или связана с такими проблемами, которые могут в долгосрочном плане перевесить преимущества этого знания. В первом случае децентрализация происходит спонтанно - как реакция на слабость центра, не способного или не готового действовать. Во втором случае децентрализация решений не сопровождается децентрализацией доступа к ресурсам, которые по-прежнему контролирует центр. В дальнейшем мы будем называть эти сценарии случаями «децентрализации слабости» и «децентрализации ответственности» и рассмотрим связанные с ними проблемы.

\section{Децентрализация слабости}

Децентрализация слабости возникает, когда центральная власть в силу разнообразных причин - политического паралича, отсутствия ресурсов или идеологических соображений в принципе не готова или не желает активно проводить антикризисную политику. В условиях пандемии коронавируса случаи Бразилии (где Президент Жаир Болсонару саботирует введение региональными властями карантинных мер) и США (где Президент и ключевые федеральные органы власти длительное время крайне медленно реагировали на развивающийся кризис) во многом соответствуют этой модели. Но другой, не менее яркий пример, - трансформационный экономический кризис 1990-х годов в России, когда слабость центральных органов власти привела к формированию многочисленных региональных стратегий адаптации, сильно отличавшихся друг от друга (Stoner-Weiss, 2002). В некоторых случаях такая адаптация была инициирована даже не региональными властями, а стала результатом спонтанной трансформации экономической системы: например, на Дальнем Востоке, где исчезновение субсидий со стороны центра привело к перестройке экономики, для которой неформальная трансграничная торговля стала важным фактором выживания (Libman, Yakovlev, 2020)

В принципе спонтанная адаптация, казалось бы, соответствует аргументам децентрализации как фактора преодоления кризиса - региональные органы власти берут на себя ответственность и самостоятельно предпринимают необходимые меры для решения возникающих проблем, с учетом региональных особенностей. Однако подобная «децентрализация слабости» сама по себе способна породить ряд проблем, оказывающих негативное влияние на экономику (возможно, в долгосрочной перспективе).

Во-первых, возникает проблема экстерналий. Предпринятые регионами самостоятельные меры могут негативно воздействовать

\footnotetext{
2 Самостоятельность отдельных земель или чрезмерная опека федерации регулярно вызывают раздражение тех или иных игроков, часто выплескивающееся на страницы СМИ, но сама модель в общем и целом функционирует. Конечно, и она обладает рядом недостатков, прежде всего низкой скоростью принятия решений.
} 
на экономическую ситуацию в других регионах, например вследствие разрыва единства экономики страны. В 1990-е годы региональный протекционизм в России, использовавшийся отдельными субъектами федерации как реакция на кризис, стал дополнительным фактором, усугубляющим рецессию. В США сегодня отдельные штаты соперничают на глобальном рынке за ставшее дефицитным медицинское оборудование, маски и защитная одежда небольшие штаты часто не могут выдержать этой конкуренции, а это, в свою очередь, не позволяет әффективно противодействовать пандемии (Soergel, 2020). Региональный эгоизм может побудить субнациональные власти игнорировать последствия их решений для других регионов или для страны в целом. Проблема негативных экстерналий не является уникальной для условий кризиса и всегда сопровождает децентрализацию, но в условиях кризиса, когда регионы предпринимают быстрые (и нескоординированные) меры, ее последствия могут быть особенно серьезными. А слабость центра не позволяет эффективно преодолеть проблему за счет координации действий региональных органов власти ${ }^{3}$.

Во-вторых, нет никакой уверенности в том, что субнациональные органы власти, принимающие самостоятельные решения, будут действительно эффективно пользоваться знанием о специфической ситуации в регионе. Их действия могут определяться идеологическими предпочтениями (в США реакция отдельных штатов на пандемию во многом определяется партийной принадлежностью губернатора (Baccini, Brodeur, 2020); в России в 1990-е годы некоторые регионы блокировали проведение рыночных реформ (Mau, Stupin, 1997)) или поиском ренты (для которого как раз на субнациональном уровне в условиях слабости центра открываются огромные возможности). Масштабы поиска ренты во многом зависят от степени подотчетности субнациональных властей местному населению (Andersson, Ostrom, 2008) и длительностью перспективы, на которую ориентируются региональные элиты (иначе говоря, их склонностью вести себя как «бродячие бандиты»в терминологии М. Олсона (см. (Libman et al., 2012)). Однако как раз в условиях кризиса подотчетность властей неизбежно снижается (в силу необходимости быстро принимать решения и неуверенности самого населения в отношении оптимальной стратегии преодоления кризиса). В некоторых политических системах может возрастать неуверенность региональных политиков в своем будущем. Все это может сделать кризисы периодом господства идеологии и поиска ренты.

В-третьих, оптимальная стратегия преодоления кризиса требует не только неформализируемого знания о специфической ситуации в регионе, но и формального экспертного знания - в некоторых случаях за здравым смыслом, основанным на опыте конкретного региона, скрываются систематические искажения в восприятии информации и принятии решений, свойственные людям (Schnellenbach, Schubert, 2015). К тому же качественно новая природа кризиса не позволяет опираться на опыт прошлого в поиске оптимальной реакции, что отчасти обесценивает преимущества «local knowledge». Между тем формальное экспертное знание с большей вероятностью будет концентрироваться в центре, а не в регионах. Координация политики между регионами и центром могла бы обеспечить баланс использования экспертного знания и неформализуемого знания о специфической ситуации в регионе, но в этом случае центр должен занимать более активную и конструктивную позицию, что в условиях «децентрализации слабости» не происходит.

Иначе говоря, децентрализация слабости позволяет в какой-то степени противодействовать кризису, но куда менее эффективно, чем в модели взаимодействия между центром и регионами (в әкономической теории используется термин «second best outcome»). Можно предполагать, что лишь некоторые регионы

\footnotetext{
${ }^{3}$ Конечно, в некоторых случаях возможна и горизонтальная координация, когда регионы взаимодействуют между собой без участия центрального правительства (см., например, Kreitner, 2020). Но организация подобной координации может занять слишком много времени, что непозволительно в условиях кризиса.
} 
смогут выработать функционирующие стратегии противодействия кризису; недостаток экспертного знания, поиск ренты, идеологические предпочтения и нехватка ресурсов приведут к принятию субоптимальных решений в других регионах, что может негативно сказаться даже на успешных субнациональных органах власти. Возникшие в условиях кризиса спонтанные модели адаптации могут превратиться в институциональные ловушки (Полтерович, 2004), в долгосрочной перспективе блокирующие развитие регионов.

\section{Децентрализация ответственности}

Другой сценарий, в котором передача полномочий регионам в условиях кризиса едва ли позволит воплотить в жизнь преимущества доступа к знанию о специфической ситуации в регионе, возникает, когда центральные органы власти хоть и делегируют регионам право принимать решения по вопросам антикризисной стратегии, сохраняют полный контроль над ресурсами и над карьерами политиков. Контроль над ресурсами, например, может быть связан с централизацией бюджетных доходов или контролем центра над ключевыми бюрократическими структурами, когда регионы вынуждены обращаться к центральным органам власти, чтобы обеспечить реализацию принятых ими мер. Контроль над карьерами политиков существует в государствах, где центр в конечном счете принимает решение о повышении или об отставке региональных администраторов (как, например, в Китае или России): в этом случае удовлетворенность центра действиями региональных политиков становится для них ключевым параметром карьерного успеха.

В описанном сценарии прежде всего әффективное противодействие кризису потребует от регионов не только оптимально использовать знание о специфической ситуации в регионе, но и участвовать в конкуренции за ресурсы в центре. Иначе говоря, успешный региональный администратор должен не только хорошо понимать ситуацию в своем регионе, но и превратиться в успешного лоббиста, способного обеспечить приток ресурсов из центрального бюджета. Анализ противодействия лесным пожарам 2010 г. в России показывает, что наиболее успешными оказались регионы, губернаторы которых сочетают преимущества знания о специфической ситуации в регионе и хороших связей на федеральном уровне (Schultz, Libman, 2015). Проблема, однако же, состоит в том, что самые сильные лоббисты далеко не всегда одновременно хорошо разбираются в ситуации в регионе более того, цель нарастить лоббистский потенциал во многом может оказаться не совместимой с целью накопить знание о специфической ситуации в регионе, потому что сильный лоббист должен много времени проводить в столице, где он может получить необходимые контакты и связи (Libman, Yakovlev, 2020). Иначе говоря, нет никакой уверенности, что «децентрализация ответственности» будет сопровождаться распределением ресурсов, от которого будут выигрывать наиболее эффективно справляющиеся с кризисом регионы.

Сохраняющийся контроль центра над карьерами региональных политиков может оказаться еще более серьезной проблемой. В такой ситуации для политиков может оказаться важнее не эффективно противодействовать кризису, а выглядеть как әффективные антикризисные менеджеры в глазах центра. В этой ситуации особенно важными становятся критерии, по которым центр оценивает успех региональных политиков. Например, политики могут вводить заведомо неэффективные меры, если они думают, что могут впечатлить центр; подстраивать свои меры под идеологические предпочтения центра или просто манипулировать статистикой (что делает противодействие кризису еще более сложным, ведь сложно противодействовать кризису, если никто не знает его реальных масштабов). Даже если центр откажется от детальных предписаний регионам относительно оптимальной стратегии реакции на кризис (что является необходимым условием использования знания о специфической ситуации в регионе региональными администрациями), он не может в принципе воздержаться/отказаться от оценивания работы чиновников, но уже само вве- 
дение формальных критериев оценки может оказаться достаточным, чтобы исказить стимулы субнациональных властей.

Децентрализация ответственности может, наконец, стать еще более рискованной стратегией, если центр отказывается от вмешательства в региональную политику или делегирует полномочия исключительно по политическим причинам - с целью передать ответственность за возможные непопулярные решения регионам. В такой ситуации региональные органы власти могут оказаться в парадоксальном положении козлов отпущения: эффективные меры, препятствующие распространению кризиса, могут одновременно снизить их популярность и привести к санкциям со стороны центра. Конечно, не все кризисы требуют принятия непопулярных решений и далеко не всегда жесткие ограничительные меры ведут к снижению популярности в краткосрочной перспективе. Наоборот, решительные региональные политики могут добиться большей поддержки в обществе в условиях кризиса. Но даже такая краткосрочная популярность может быстро улетучиться по мере нарастания связанных с кризисом противоречий.

Иначе говоря, децентрализация ответственности хотя и кажется мерой, увеличивающей возможности для использования знания о специфической ситуации в регионе, на практике эта мера может даже содействовать принятию субнациональными властями неоптимальных решений. Асимметрия информации между центром и регионами может сделать децентрализацию ответственности худшим сценарием, чем простое централизованное принятие решений, например, если регионы начнут определять свою политику, пытаясь угадать желания центра и, соответственно, принимать решения, не только противоречащие логике «local knowledge», но и не полностью соответствующие той политике, которую пытается проводить центр.

\section{Выводы}

Подведем основные итоги нашего анализа. Кризисы действительно могут стимулировать децентрализацию, однако децентра- лизация далеко не всегда содействует поиску эффективных решений на основе знания о специфической ситуации в регионе. Все зависит от того, какие условия порождают децентрализацию и какую роль продолжает играть центр. Децентрализация слабости и децентрализация ответственности представляют собой два негативных примера воздействия кризиса на отношения центра и регионов. Пандемия Covid-19, действительно ведущая к росту активности регионов во многих странах мира, во многих случаях проходит именно по одному из этих двух сценариев (Sharma, 2020).

Россия не является исключением. Последние десятилетия стали периодом последовательной централизации и ослабления автономии регионов. Стагнация, в которой российская экономика находится с 2013 г., позволяла строить предположения, что в какой-то момент региональные губернаторы будут вынуждены занять более активную и самостоятельную позицию в отношениях с центром (Libman, 2016), но вплоть до 2019 г. федеральный центр сохранял полный контроль над субъектами федерации. Пандемия привела к формальному смещению центра принятия антикризисных решений на уровень регионов. Однако субъекты Федерации по-прежнему зависят от Москвы с точки зрения финансовых ресурсов, а их губернаторы - от президента с точки зрения их дальнейшей карьеры. Все это соответствует скорее логике «децентрализации ответственности» (Крашенинников 2020; Перцев, 2020; Lipman, 2020), которая в отдельных случаях (когда центр устраняется от принятия решений или реагирует слишком медленно) может перейти в «децентрализацию слабости». Такая модель не только не обязательно способствует преодолению кризиса, но и в долгосрочном плане едва ли станет основой для экономического роста.

\section{ЛИТЕРАТУРA / REFERENCES}

Крашенинников Ф. (2020). «Коронация губернаторов»: эпидемия и перспективы отмены выборов // Republic.ru. 13 мая. Режим доступа: https://republic.ru/ posts/96701 [Krasheninnikov F. (2020). 
Crowning of the governors: Epidemic and the perspective of abolition of elections. Republic.ru, May 13. Available at: https:// republic.ru/posts/96701 (in Russian).].

Перцев А. (2020). Вирусный федерализм. Как эпидемия обнажила устройство региональной власти в России. Московский центр Карнеги, 7 апреля. Режим доступа: https://carnegie.ru/commentary/81480 [Pertsev A. (2020). Virus federalism: How pandemics showed the organization of regional power in Russia. Carnegie Moscow Center, April 7. Available at: https: / / carnegie.ru/ commentary/81480 (in Russian).]

Полтерович В.М. (2004). Институциональные ловушки: есть ли выход? Общественные наужи и современность. № 3. C. 5-16. [Polterovich V.M. (2004). Institutional traps: Is there a way out? Social Sciences and Contemporary World, 3, 5-16 (in Russian).]

Andersson K.P., Ostrom E. (2008). Analyzing decentralized resource regimes from a polycentric perspective. Policy Sciences, 41 (1), 71-93.

Arias L.M. (2013). Building fiscal capacity in colonial Mexico: From fragmentation to centralization. Journal of Economic History, 73 (3), 662-693.

Baccini L., Brodeur A. (2020). Explaining governors' response to the COVID-19 pandemic in the United States. Mimeo.

Bolgherini S. (2016). Crisis-driven reforms and local discretion: An assessment of Italy and Spain. Rivista Italiana di Scienza Politica, 46 (1), 71-91.

Flanagan R.M. (1999). Roosevelt, mayors and the New Deal regime: The origins of intergovernmental lobbying and administration. Polity, 31 (3), 415-450.

Hayek F.A. (1945). The use of knowledge in society. American Economic Review, 35 (4), 519-530.

Kreitner R. (2020). When confronting the coronavirus, federalism is part of the problems. The Nation, 1 April. Available at: https:// www.thenation.com/article/politics / federalism-coronavirus-problem-government/
Libman A. (2016). Consequences of informal autonomy. Berlin: Peter Lang.

Libman A., Kozlov V., Schultz A. (2012). Roving bandits in action: Outside option and governmental predation in autocracies. Kyklos, 65 (4), 526-562.

Libman A., Yakovlev A. (2020). A centralist approach to regional development: The case of the Russian Ministry for the Development of the Far East. Europe-Asia Studies (forthcoming).

Lipman M. (2020). Verplatzte Krönung: Putins Verfassung und das Corona-Virus. Osteuropa, 70 (3-4), 3-12.

Mau V., Stupin V. (1997). The political economy of Russian regionalism. Communist Economies and Economic Transformation, 9 (1), 5-25.

Schnellenbach J., Schubert C. (2015). Behavioral political economy: A survey. European Journal of Political Economy, 40, 395-417.

Schultz A., Libman A. (2015). Is there a local knowledge advantage in federations? Evidence from a natural experiment. Public Choice, 162 (1-2), 25-42.

Sharma M. (2020). Coronovirus is straining the concept of federalism. Bloomberg, 3 May. Available at: https://www.bloomberg.com/ opinion/articles / 2020-05-03/coronavirus-crisis-is-straining-the-concept-of-federalism

Sobel R.S., Leeson P.T. (2007). The use of knowledge in natural-disaster relief management. Independent Review, 11 (4), 519-532.

Soergel A. (2020). States competing in global jungle for PPE. US News, 7 April. Available at: https://www.usnews.com/news / beststates / articles / 2020-04-07/states-compete-in-global-jungle-for-personal-protective-equipment-amid-coronavirus

Stoner-Weiss K. (2002). Local heroes: The political economy of Russian regional governance. Princeton: Princeton University Press.

t'Hart P., Rosenthal U., Kouzmin A. (1993). Crisis decision making: The centralization thesis revisited. Administration E Society, 25 (1), 12-45.

Tofall N.F. (2020). Föderalismus ist gerade in Krisen wie der Corona-Krise notwendig. Flossbach von 
Storch Research Institute Commentary. Available at: https://www.flossbachvonstorchresearchinstitute.com/de/kommentare/ foederalismus-ist-gerade-in-krisen-wie-dercorona-krise-notwendig/
Wallis J.J. (1984). The birth of the old federalism: financing the New Deal, 1932-1940. Journal of Economic History, 44 (1), 139-159.

Поступила в редакиию 8.05.2020

Received 8.05.2020

\section{A.M. Libman}

Ludwig Maximilian University of Munich, Germany

\section{Decentralization of crisis, weakness and responsibility}

Abstract. Crises frequently weaken subnational governments but in some cases they lead to greater decentralization. Does this decentralization, however, support the search for optimal crisis response strategies? Generally speaking there are several arguments, which suggest that decentralized systems will manage crises better than centralized ones. This article, however, considers two scenarios (decentralization of weakness and decentralization of responsibility) where the apparently increasing autonomy of subnational governments leads to important problems. Decentralization of weakness emerges when the central government for certain reasons refuses to actively implement an anti-crisis policy. Under these conditions, regional measures, while to some extent compensating the inactivity of the central government, create a number of other problems - that of external effects, possible ideologization of politics and insufficient use of expert knowledge. Decentralization of responsibility emerges when regions accept responsibility for implementing anti-crisis measures, but the center keeps control over resources - thus, regions have to focus on competing for central financing. For the modern Russia, the risks of these two scenarios are substantial.

Keywords: decentralization, crisis, local knowledge.

JEL Classification: H12, H77.

DOI: $10.31737 / 2221-2264-2020-46-2-10$

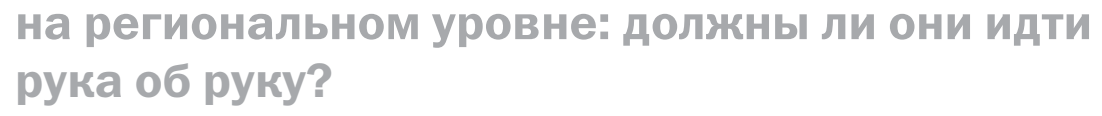

Аннотация. В этой работе мы показываем существование положительной ассоциативной связи между сложностью экономики и уровнем высшего образования как на уровне стран мира, так и на уровне российских регионов. В случае последних мы получаем более высокую дисперсию сложности образовательной по сравнению с экономической. Мы обнаруживаем регионы, в которых развитие системы высшего образования, измеренное при помощи индекса сложности высшего образования, заметно опережает развитие соответствующей региональной әкономики, измеренное при помощи индекса экономической сложности. Так как процесс усложнения әкономик регионов скорее всего будет связан с высокими рисками неудач, затратами и продолжительным временем, более развитая система высшего образования может слабо влиять на развитие соответствующих региональных экономик. Из этого, однако, не следует делать вывод о том, что процесс выравнивания качества высшего образования в регионах должен быть свернут. Дальнейшее развитие системы опорных университетов уже сегодня служит сокраще- 